\title{
GREASE TRAP WASTE: A HEADACHE OR A VALUABLE ENERGY SOURCE?
}

\author{
Ji Xing ${ }^{1,2}$ \\ Marcia Marques ${ }^{2,3}$ \\ $\mathrm{Li} \mathrm{Li}^{4}$

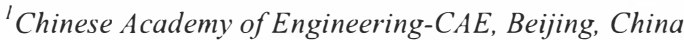 \\ ${ }^{2}$ University of Kalmar, Sweden \\ ${ }^{3}$ Rio de Janeiro State University-UERJ, Brazil \\ ${ }^{4}$ China National Petroleum Corporation, China
}

\begin{abstract}
In this article, the grease trap waste (GTW) is defined and its composition is discussed. The management strategy, including collection, transportation, separation and treatment of GTW is briefly discussed. Technological options currently used including landfill, fermentation for biogas, separation of oil from water and other organic matters by boiling are also mentioned. The state of the art regarding energy from GTW in developed countries like Singapore, Australia and USA and developing countries including China is addressed and the first-hand data are collected. The "zero-energy consumption, no mal odor emission" GTW separation technology is presented. The pilot GTW to bio-diesel plant in small and medium- sized cities like Neiqiu and Xingtai in Hebei Province, China, shows that the conception of waste to energy is technologically, environmentally and economically feasible. Academic studies and engineering practice show that, if GTW is rationally managed, it is an important energy source to mankind; otherwise, it creates constraints in treatment facilities.
\end{abstract}

\section{KEYWORDS}

grease trap waste; waste to energy; bio-diesel; brown grease

\section{INTRODUCTION}

Biodiesel presents an important alternative fuel for transport currently run on diesel fuel and is usually produced from food-grade vegetable oils that are currently more expensive than diesel fuel [1]. Waste cooking oils, restaurant grease and animal fats are potential feed stocks for biodiesel. These inexpensive feed stocks represent one-third of the US total fats and oil production, but are currently devoted mostly to industrial uses and animal feed [1]. The characteristics of feedstock are very important during the initial research and production stage. In general, all greases and oils are classified as lipids. Chemically, greases and oils are classified as triglycerides. However, oils are generally considered to be liquids at room temperature, while greases and fats are solid at room temperature.

\subsection{Definition of yellow and brown (trap) grease}

Greases are generally classified in two categories, yellow grease and brown grease. The main sources of animal fats are primarily meat animal processing facilities. Another source of animal fats is the collection and processing of animal mortalities by rendering companies. 
Yellow grease is produced from vegetable oil or animal fat that has been heated and used for cooking a wide variety of meat, fish or vegetable products [1]. In USA, renderers filter out the solids and heat the spent cooking oil to drive out moisture until it meets industry specifications for yellow grease. The amount of yellow grease feedstock collected from restaurants in 30 randomly selected metropolitan areas in USA [2] ranged from about 1.4 to $9.5 \mathrm{~kg} /$ year/person or about 900 to $5,900 \mathrm{~kg} /$ year/restaurant for the metropolitan areas sampled in that study. Yellow grease is required to have a free fatty acid (FFA) level of less than $15 \%$ [1]. If the FFA level exceeds $15 \%$, it is called brown grease, sometimes referred to as trap grease that may be sold at a discount, or blended with low FFA material to meet the yellow grease specifications [1]. Trap grease or grease trap waste (GTW) is material that is collected in special traps in restaurants to prevent the grease from entering the sanitary sewer system where it could cause blockages. Many rendering plants will not process trap grease because it is usually contaminated with cleaning agents. These cleaning agents may not themselves be hazardous but they make detection of harmful substances more difficult. These grease floats on the surface of the water in the grease trap while the dishes are washed. GTW it is a kind of grey-to-black viscous gel-like semi-solid waste with a very strong mal-odor whose density is about $880 \mathrm{~kg} \mathrm{~m}^{-3}[3]$.

\subsection{GTW formation}

Oily materials like fried flour and meat waste do not absorb water when they are flushed into the grease trap. In a typical Chinese restaurant, when steamed, noodles flushed into the grease trap will not absorb oil, because in the steaming process, they are saturated with water due to absorption, while in the grease trap, steamed noodles are adhered to other materials by the grease, which covers its surface and does not penetrate into the inner part of the noodles. Baked cake and other food wastes without being steamed, or steamed cake, rice and noodles, when partially dried, will absorb water and grease at the same time, after they were flushed into the grease trap full of water and grease. In this absorption process, the absorption of water and plant oil compete with each other, and the absorption happens on the surface of these food waste. The absorption of water dominates the whole absorption process, the absorption of plant oil holding the second position after that of water absorption [3]. The animal fat will block the absorption hole in the foodstuffs, which prevents the food- wastes absorbing the water and plant oil. The animal fat is mixed with the flour food wastes and other materials. The rule of absorption water, plant oil and animal fat in the flour food wastes is that the absorption of oil in the food waste will lead to non-absorption of water, and the absorption of water will lead to non-absorption of oil. Other materials including pepper, vegetable leaves, melon seeds, bunge prickly ash fruit, if they are oil-fried, will absorb oil and will not absorb water in the grease trap, and if they are not oil-fried, they will tend to absorb water, and the absorption of water exceeds that of the plant oil. Those materials with a

saturation of oil or water separately, or with a saturation of both water and plant oil, suspend in the mixture of the flour and oil, and are adhered to other materials by the grease. The unknown gel-like materials go over a process of saturated absorption of water and grease, and their absorption behavior and mechanism need a further study. When the unknown gel-like continuous phase is destroyed, $50 \%$ of the solid materials sink to the bottom of the water and do not contain any oil. GTW, which forms a continuous phase of water, gel-like materials and other solid materials (with flour food waste as the main component) with grease as an adhesive, are very difficult to separate. The grease trap and the structure of GTW are shown in Figures 1 and 2. 


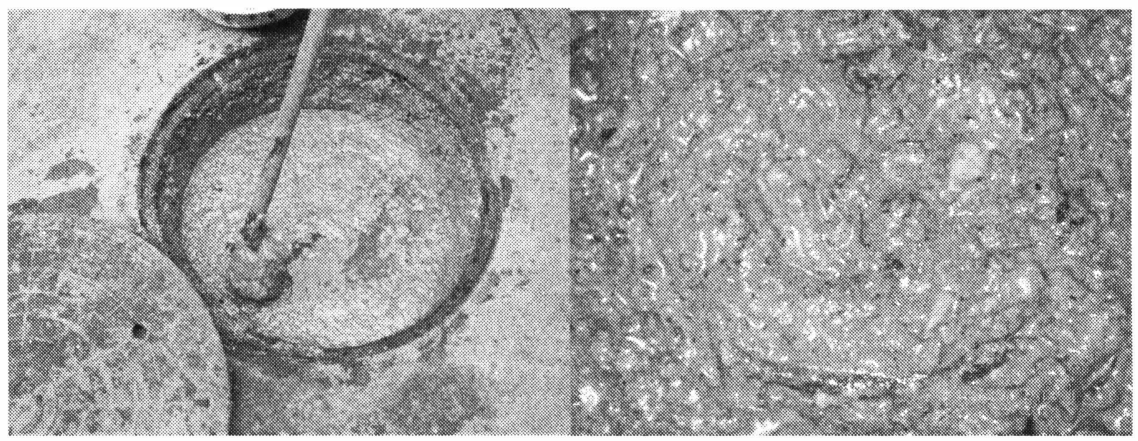

Figure 1. The grease trap from the top.

Figure 2. The structure of GTW.

Based on their chemical properties, gel like materials, are the most difficult substances to be separated; however, GTW, as a mixture of water, grease, hydrophilic and hydrophobic substances, is the most difficult mixture to be separated. Normally, GTW is not properly characterized. It refers to any waste in the grease trap. This definition leads to a significant increase of the quantity of GTW and a lot of waste water is irrationally transported into waste water treatment plants specially operated for GTW disposal, thus a lot of oily waste water is produced from the treatment of GTW, because a lot of water is wrongly incorporated into GTW. Though GTW and kitchen leftover are all produced from the kitchen, but they are totally different, for kitchen leftover can be divided into two categories: waste vegetable leaves and food waste, which are not flushed into the waste water pipe and grease trap, while GTW is the only component flushed into the grease trap. Besides, the detergent content in GTW is much higher than that in the kitchen leftover.

\section{COLLECTION, TRANSPORTATION AND MANAGEMENT POLICY}

In Singapore, Hong Kong, Australia and USA, the Environment Protection Agencies are responsible for the whole reuse chain of GTW. In China however, different government sectors in different cities of China are responsible for the collection, transportation, treatment, reuse of GTW and other grease waste. For example, in Beijing, it is the Beijing Municipal Administration Commission that is responsible for GTW collection, while in Shanghai it is the Environment Protection Agency that is responsible for this matter. In China, there is not a complete and feasible governmental circular by which to administrate GTW issues. In Hong Kong, a "Grease Trap Waste Disposal Control" was prepared by the EPD to administrate the GTW related matters. However, in the Chinese mainland, due to the lack of specific regulations in this area, the collection, transportation and treatment of GTW and other waste grease is actually out of control. CCTV, China's top TV station, has broadcasted several times the illegal business that uses the grease waste to fry edible food for human beings. At the same time, grease waste that could be a resource for the bio-diesel industry is either drained into the waste water system, wasted, or illegally mixed into the edible oil for humans or animals. The third problem is that there is no national standard to regulate the treatment process of GTW, so as a result, there is too much pollution produced in the treatment process including oily waste water, strong mal-odor. The other consequence for the lack of the standard is that the advanced environment friendly extraction technology cannot be effectively and widely put into use and the whole technological level of GTW extraction is at a very low level. The fourth problem is that due to lack of management by the government, 
the pricing mechanism is fragile. For instance, due to over-investment in the bio-diesel industry, the price of the waste grease from GTW roars high, from 1,800 Yuan in 2002 to 3,600 Yuan per ton in 2006 [4]. As a consequence, the high price has limited the wide use of waste grease in the bio-diesel industry, thereby in return causing the consumption of waste grease to be reduced, so those involved in the waste grease conversion does not get the expected profit.

\section{BRIEF EVALUTATION OF EXISTING TECHNOLOGICAL PROCESSES}

Nowadays there are several technological processes to deal with GTW, including landfill for use as agricultural fertilizer, fermentation for biogas, separation of oil from water and other organic matters by boiling "zero-energy consumption, no mal-odor emission GTW separation technology" [3]. Here these technological processes with the parameters like energy consumption, mal-odor emission, waste water discharge, product, solid waste disposal, treatment capacity, technological maturity, and the feasibility of large-scale use are briefly evaluated. Table 1 presents a comparative analysis of different GTW disposal options. It is worth notice that the fermentation mechanism responsible for grease to be transformed in biogas is not clear. Some experts argue that grease be converted to bio-gas, while others say that the fatty acids in the grease restrain the fermentation and the grease itself cannot be converted to biogas.

Table 1. Comparative analysis of different options for GTW disposal.

\begin{tabular}{|c|c|c|c|c|}
\hline $\begin{array}{r}\text { Technological } \\
\text { Process }\end{array}$ & $\begin{array}{l}\text { Landfill for use } \\
\text { as agricultural } \\
\text { fertilizer }\end{array}$ & $\begin{array}{c}\text { Fermentation for } \\
\text { biogas }\end{array}$ & $\begin{array}{l}\text { Separation of oil } \\
\text { from water and } \\
\text { other organic } \\
\text { matters by } \\
\text { boiling }\end{array}$ & $\begin{array}{l}\text { "Zero-energy } \\
\text { consumption, no } \\
\text { mal-odor emission } \\
\text { GTW separation } \\
\text { technology" }\end{array}$ \\
\hline $\begin{array}{c}\text { Energy } \\
\text { consumption }\end{array}$ & $\begin{array}{l}\text { No energy } \\
\text { consumption }\end{array}$ & $\begin{array}{c}\text { No energy } \\
\text { consumption in hot } \\
\text { summer; } \\
\text { Little energy } \\
\text { needed in winter to } \\
\text { keep warm }\end{array}$ & $\begin{array}{l}\text { Large energy } \\
\text { consumption }\end{array}$ & $\begin{array}{c}\text { No external energy } \\
\text { needed }\end{array}$ \\
\hline $\begin{array}{l}\text { Mal-odor gas } \\
\text { emission }\end{array}$ & $\begin{array}{l}\text { Mal-odor gas } \\
\text { emission if not } \\
\text { covered with } \\
\text { earth }\end{array}$ & $\begin{array}{c}\text { No mal-odor } \\
\text { emission in a } \\
\text { fermentation } \\
\text { process; } \\
\text { mal-odor emission } \\
\text { when discharged }\end{array}$ & $\begin{array}{l}\text { Strong mal-odor } \\
\text { emission }\end{array}$ & $\begin{array}{l}\text { No mal-odor } \\
\text { emission }\end{array}$ \\
\hline $\begin{array}{l}\text { Waste water } \\
\text { discharge }\end{array}$ & No & Oily waste water & $\begin{array}{c}\text { Heavy oily } \\
\text { waste water } \\
\text { discharge }\end{array}$ & $\begin{array}{l}\text { Clean water } \\
\text { discharge }\end{array}$ \\
\hline Product & no & $\begin{array}{l}\text { Bio-gas, } \\
\text { agricultural } \\
\text { fertilizer }\end{array}$ & $\begin{array}{c}\text { Oil for chemical } \\
\text { use }\end{array}$ & $\begin{array}{c}\text { Oil for bio-diesel; } \\
\text { Water for } \\
\text { agricultural use; } \\
\text { Solid waste for fuel } \\
\text { use }\end{array}$ \\
\hline
\end{tabular}


Kalmar ECO-TECH '07

KALMAR, SWEDEN, November 26-28, 2007

Kalmar ECO-TECH '07

KALMAR, SWEDEN, November 26-28, 2007

Table 2. Comparative analysis of different options for GTW disposal.(Continued)

\begin{tabular}{|c|c|c|c|c|}
\hline $\begin{array}{c}\text { Solid waste } \\
\text { disposal }\end{array}$ & no & Sludge & sludge & $\begin{array}{c}\text { Solid waste for fuel } \\
\text { use }\end{array}$ \\
\hline $\begin{array}{c}\text { Treatment } \\
\text { capacity }\end{array}$ & large & Large & Small & large \\
\hline $\begin{array}{c}\text { Technological } \\
\text { maturity }\end{array}$ & mature & mature & Outdated & Industrial trial scale \\
\hline $\begin{array}{c}\text { Feasibility of } \\
\text { large scale use }\end{array}$ & Feasible & Feasible & Small & To be determined \\
\hline
\end{tabular}

\section{SEPARATION OF GREASE FROM GTW}

As mentioned in the front part of this article, the complex composition and structure of the GTW makes it very difficult to be separated. The problem with processing waste oils is that they usually contain large amounts of free fatty acids that cannot be converted to biodiesel using an alkaline catalyst due to formation of fatty acid salts (soap) $\notin 1]$. The soaps can prevent separation of the biodiesel from the glycerin fraction. An alternative method is to use acid

catalysts, which are able to esterify free fatty acids [5]. At first, the guiding method of separation focuses on the extraction of oil. A lot of methods were developed, including the natural flotation, IR and micro wave enforced natural flotation, high pressure and normal pressure filtration, high speed centrifugal separation [3]. However, most of these methods have been proved ineffective and/or impractical. Some methods are presented and briefly discussed.

\subsection{The natural floatation and IR, micro-wave enforced natural floatation}

The theoretical basis for the natural floatation is that the density of the grease is $0.80-0.90 \mathrm{~g}$ $\mathrm{cm}^{-3}$, lighter than the water, which is $1 \mathrm{~g} \mathrm{~cm}^{-3}$; so, when the GTW is exposed to the sunlight, grease will float on the surface of the water; then, the grease can be taken out of the GTW. However, the separation speed is very slow, and only $30 \%$ of the total grease can be taken out, while a lot of grease is still mixed with the hydrophobic substances, in this case, it can be separated from the GTW though enrichment at the upper layer of the GTW. The weak points of this method are obvious. On one hand, the fermentation increases and the FFA in the grease increases, too, which acts as the detergent and makes the separation of the grease from the GTW more difficult; on the other hand, the mal-odor gas emission is always complained about by the inhabitants nearby. Besides, this method is always affected by the weather- the wind, rain and snow will destroy the separation process. Even though, it is still being used in some countries in tropic and subtropical zones. It is obvious that this method is not feasible for the countries in frigid zones. In north European counties like Sweden, this method is not practical.

In order to expand the application area of this method, two improvements can be made, based on the natural floatation method: (i) the first improvement is its combination with the manmade greenhouse, and (ii) the second is its combination with the IR. The artificial green house proves not effective because of the heat radiation to the outside environment, so it will consume too much energy to make the green house warm enough, and the green house itself is seriously affected by the weather. As the water molecular chain and grease molecular chain 
have different vibration frequencies, IR with different frequencies are applied to heat the water and grease respectively [3]. When special IR is applied to heat water, the water molecular chain has a process of very strong absorption of this frequency and is greatly vaporized at a very low temperature, but the gel keeps stable, which demonstrates that the water is not the main factor keeping the gel stable. The temperature of the gel increases while the viscosity reduces with the increase of the radiation time [3]. But when the temperature reaches $70{ }^{\circ} \mathrm{C}$, the grease melts and floats up to the surface of the water. When special I.R. is applied to grease according to the vibration frequency of grease, the viscosity of the grease reduces very quickly, and the gel is totally and quickly destroyed, the grease separated quickly from the water and solid waste, and floats to the surface of the water. When the grease-fitting frequency is applied, the grease will float to the surface of the water at 30-60 ${ }^{0} \mathrm{C}$, which is lower than the temperature when the water-fitting frequency was applied. An agitator has to be applied to give help so that the whole GTW can be heated because the radiation depth is only $2-3 \mathrm{~cm}$. The microwave with a frequency of $915 \mathrm{MHz}$ and $2450 \mathrm{~Hz}$ was proved to be very effective in the separation of the waste grease from the GTW, but in this case, the water is heated at the same time, which causes much energy consumption and makes it infeasible to be widely used on the industrial scale.

\subsection{High pressure filtration method}

\subsubsection{The effect of the high pressure on the separation of grease from GTW}

Figure 3 illustrates a high-pressure separation system tested for separate grease from GTW. The effect of pressure on the separation of grease from GTW is shown in Figure 4 and the effect of pressure on the volume change of GTW is shown in Figure 5. As the water content in the GTW is much higher than that in the normal oil-rich seeds like rape seeds and the solid waste is non-compressible, it can be seen from Figure 5 that the volume of GTW reduces only $6 \%$ when the pressure is $1-2 \mathrm{~atm}$; when the pressure increases, the volume will not decrease any more, which shows that the pressure on the separation of grease from GTW will not be effective any longer; the pressing process is of static pressure-rising and the particles in GTW hold its original position and do not move, and there is no significant site change in the process. Thus, the grease release channel will be closed at the early stage of the pressing process and only a small portion of grease and water near the sand and filter is pressed out of the GTW. It can be seen from Figure 4, water and grease are pressed out of the GTW at a low temperature, but when the pressure increases, no more grease and water can be pressed out, showing that the grease -released channel is closed at this time, and that the pressure will not be effective any longer. When the equipment is decomposed, it is found that only the GTW near the sand with the height of $2 \mathrm{~cm}$ is pressed to be a hard cake and the inner part of GTW does not change its original composition. The result shows that the static pressing method is not suitable for the separation of grease from GTW. 
Kalmar ECO-TECH '07

KALMAR, SWEDEN, November 26-28, 2007

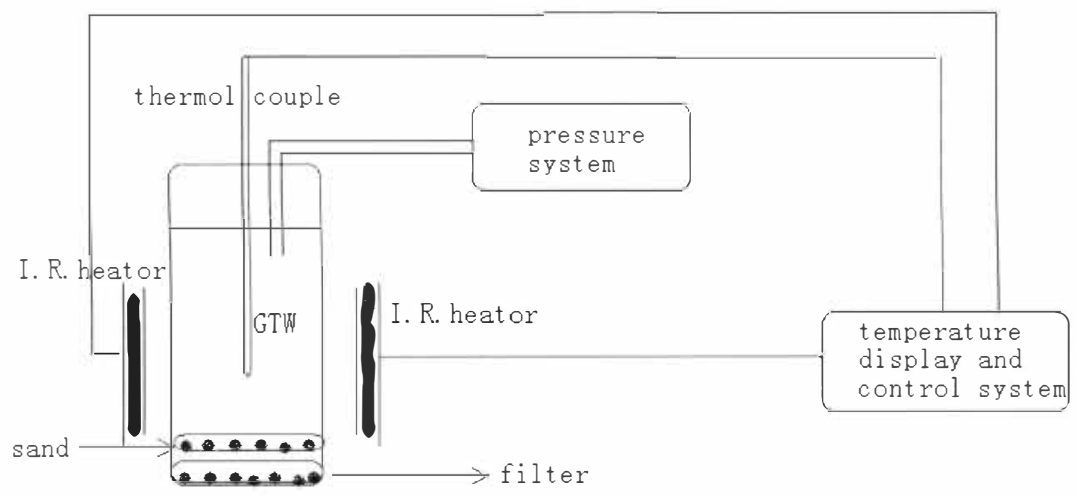

Figure 3. High-pressure separation system of grease from GTW [3].

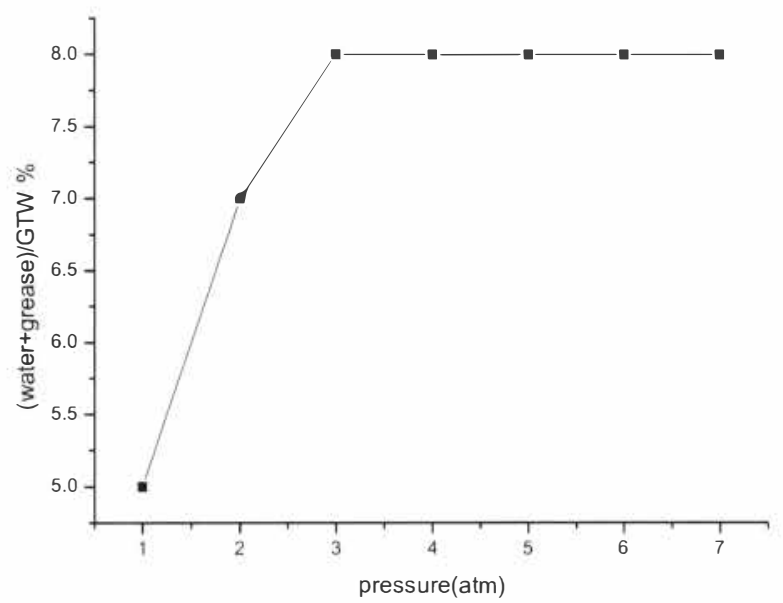

Figure 4. The effect of pressure on the separation of grease from GTW [3]. 
Kalmar ECO-TECH '07

KALMAR, SWEDEN, November 26-28, 2007

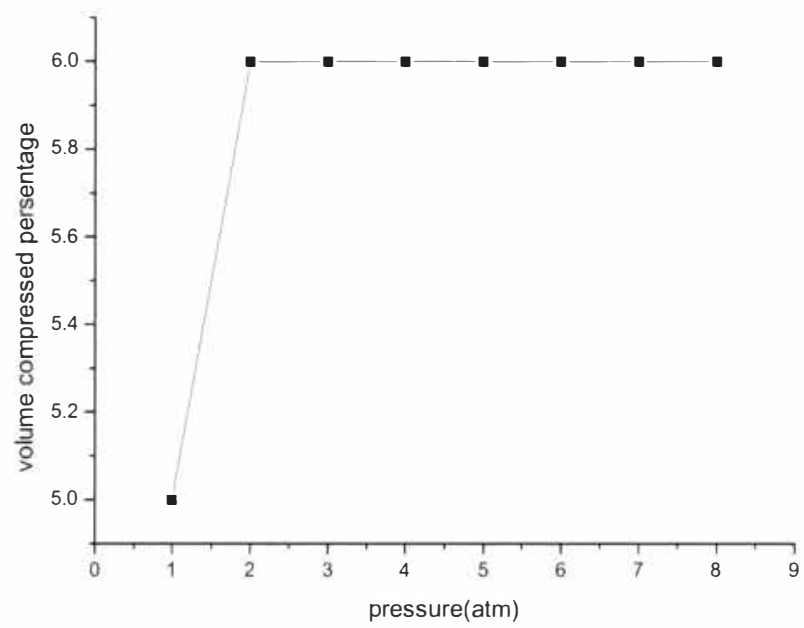

Figure 5. The effect of pressure on the volume change of $\Theta T W[3]$.

\subsubsection{The effect of temperature on the separation of grease from GTW}

The effect of temperature on water plus grease ratio to GTW is shown in Figure 6. The grease content in the liquid at different temperatures is shown in Figure 7.

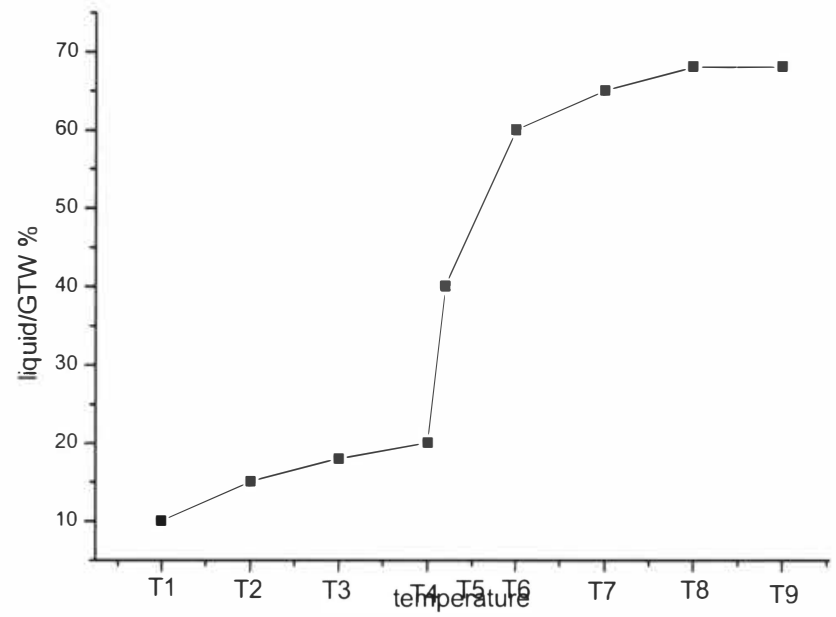

Figure 6. The effect of temperature on water plus grease ratio to GTW [3]. 


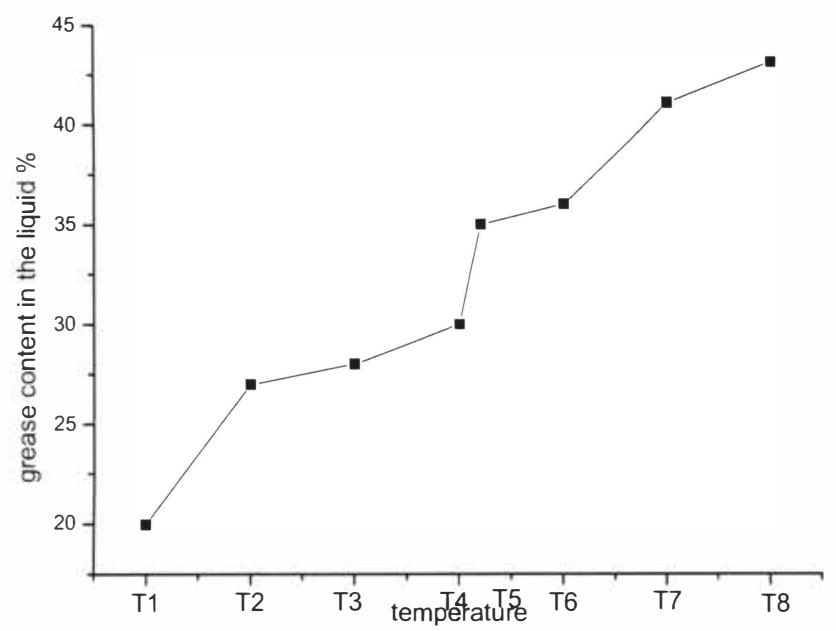

Figure 7. The grease coneent in the liquid at different temperatures [3].

It can be seen from Figures 6 and 7 that, with the temperature to increase, the viscosity of GTW decreases significantly. So does the grease releasing speed at the same time and pressure as well. So does the grease content in the liquid. This shows the temperature destroys

the continuity of the GTW phase. However, if the temperature is too high, the chemical property of both the hydrophilic and hydrophobic substances will change, the water will vaporize, and the energy consumption increases as a result. There is an optimum temperature to different kinds of GTW, but when the working temperature is lower than this optimum temperature, there is only some unsaturated grease in the liquid grease. With the working temperature to increase, the content of saturated grease in the grease increases significantly, and when the working temperature rises to the water-vaporizing temperature point, the grease comes out of the GTW system with the steam at a very high speed; however, the grease content in the liquid decreases. It is estimated that the liquid grease competes with the steam to come out of the GTW through the same channel, and the water releasing speed is higher than that of the grease, so the steam comes out of the GTW system more quickly than grease. It is worth our attention that when the steam begins to come out of the GTW system, the grease releasing speed increases significantly. This is because the steam takes the grease out of the system. So it is the same with the steam distillation in organic chemistry. However, as the components of the GTW are non-compressive, the grease release channel will be closed quickly, which causes the grease and water to be trapped in the closed channel. Thus, the static pressing is not suitable for the separation of GTW.

\subsection{High speed centrifugal separation}

When GTW is introduced into a high-speed centrifugal separation machine with a rotary speed of $10,000 \mathrm{r} / \mathrm{min}$, the water and liquid grease can be quickly separated separately from 
the GTW; however, the solid waste destroys the rotational balance of the machine and makes it unable to work any longer, so how to get the solid waste out of the machine remains a problem. A high speed centrifugal separation machine is designed for the mixture with the content of solid materials lower than $2 \%$ and smaller than 60 meshes, so the GTW is not suitable for the high speed centrifugal separation system. Besides, the strong mal-odor and the erosion to the equipment make it more difficult to use the high speed centrifugal separation system for GTW.

\section{4 "Zero-energy consumption, no mal-odor emission GTW separation technology"}

According to the high-pressure separation method, it is infeasible in the eye of engineering to separate grease from GTW without the separation of the solid waste from the water. The new described by [3] is based on the simultaneous separation of grease and water and solid waste at the same time, instead of the separation of grease only. This is the difference between the common separation method and the chaos separation method. The grease, water and solid waste are separated simultaneously according to the chaos separation theory, and gel-like substances act as the filtration material to water and grease; when the water and grease is separated from the solid, the gel itself will become part of the solid waste. Thus, the gel will be of help instead of the barrier for separation. Hydrophilic and hydrophobic substances act as the filter for grease and water respectively, and they themselves will lose oil and water at the end of the separation and become solid materials. The main characteristic of this method is that no mal-odor gas is emitted in the process and the solid waste obtained af ter the separation can be used as fuel for the separation process, so no external energy will be needed, and there is zero energy consumption in the process. And in the hot summer time, it will produce energy in the process for external use.

Engineering practice: Based on the chaos separation theory, a pilot separation plant has been set up in Neiqiu County, He Bei Province (north China), with GTW (Table 2) supplied by a catering industry from Xingtai City with a population of about 380,000, and two service stations beside the express way from Beijing to Zhuhai City (south China).

Table 2. Composition of GTW entering the Neiqiu pilot plant, north China [3].

\begin{tabular}{|c|c|c|}
\hline \multirow{4}{*}{$\begin{array}{l}\text { Basic } \\
\text { property }\end{array}$} & Specification & Item \\
\hline & density $\mathrm{g} / \mathrm{cm}^{3}$ & $0.85-0.94$ \\
\hline & Form, odor and color & $\begin{array}{l}\text { grey viscous, gel-like } \\
\text { semi-solid with strong } \\
\text { mal-odor }\end{array}$ \\
\hline & Melting point ${ }^{\circ} \mathrm{C}$ & $16-30$ \\
\hline \multirow{5}{*}{ Composition } & Grease & $30-50 \%$ \\
\hline & Solid waste & $25-35 \%$ \\
\hline & $\begin{array}{c}\text { Larger than } 60 \text { meshes: peppers, vegetable } \\
\text { leaves, wood chopsticks, melon seeds, noodles, } \\
\text { etc }\end{array}$ & $5-10 \%$ \\
\hline & $\begin{array}{l}\text { Less than } 60 \text { meshes; flour-based foodstuffs } \\
\text { and unknown gel-like materials }\end{array}$ & $20-25 \%$ \\
\hline & Water & $30-40 \%$ \\
\hline
\end{tabular}


The total amount of GTW supplied is about 4-6 tons per day. The composition of the GTW processed in this plant is shown in Table 2. Based on investigations carried out in Australia [6], it was estimated that less than $10 \%$ of the total volume collected as grease trap waste was actually fat, with the remainder consisting of water, food scraps and general rubbish trapped by the system. It can been seen that the water content in the GTW in the Neiqiu pilot plant is much less than other reports and scientific publications because here, the GTW is collected either by hand or by a special designed pump, resulting in less water in the pumping process. The separation time is about 4-8 hours. The quality of the grease obtained is shown in Table 3. The properties of waste grease from GTW are between pig fat and mutton fat, which is a mixture of animal fat and plant oil [3]. It is worth noticing that the water content in the grease obtained from GTW is less than $0.5 \%$ and can be directly used as raw material for bio-diesel. The oil content in the solid waste is less than $1 \%$ and the water content is less than $2 \%$, there being no oil in the water. In China, national standards for the extraction process of GTW is being drafted based the working condition in this pilot plant. In the long run, it is expected that the engineering practice in this pilot plant and the national standard based on it will help to upgrade the technological level of China's GTW treatment industry to get rid of the outdated extraction technology by the market force.

Table 3. Properties of the grease GTW in the Neiqiu pilot plant.

\begin{tabular}{lcccc}
\hline Item & Density & Melting point ${ }^{\circ} \mathrm{C}$ & Acid value & Color \\
\hline Waste grease & $0.90-0.961$ & $42-50$ & $30-160$ & Yellow brown \\
\hline Animal fat from pork & $0.89-0.006$ & $32-45$ & 4 & Light brown \\
\hline Mutton fat & $0.93-0.963$ & $44-49$ & 5 & White \\
\hline
\end{tabular}

\section{WASTE GREASE FROM GTW CONVERSION TO BIO-DIESEL}

The dominant technological process converting GTW to bio-diesel includes the pretreatment, and then esterification plus trans-esterification, and then vacuum distillation [3]. The widely used catalyst is acid, alkali or modified acid and alkali, as the acid value of the raw material is very high. The reserved catalyst is lipase. Another reserved technology is super-critical reaction without any catalyst. The bio-diesel yield is about $80-90 \%$. The quality of the bio-diesel produced is shown in Table 4.

Table 4. Quality of biodiesel produced from GTW [3].

\begin{tabular}{lc}
\hline Item & Measured data \\
\hline Density kg m & -3 \\
\hline Flashing point ${ }^{0} \mathrm{C}$ & 880 \\
\hline Freezing point ${ }^{0} \mathrm{C}$ & 146 \\
\hline Sulphur content & $2-4$ \\
\hline Ash \% & 0 \\
\hline Water contente $\%$ & $0.01 \%$ \\
\hline Copper erosion & $0.01 \%$ \\
\hline Cetane index & Grade 1 \\
\hline Oxidation stability (with additive) $\mathrm{h}$ & 55 \\
\hline Acid value in $\mathrm{mg} \mathrm{KOH} / \mathrm{g}$ & $6.2 \mathrm{~h}$ \\
\hline Free glycerol $\%$ & 0.5 \\
\hline Total glycerol \% & $0.016 \%$ \\
\hline
\end{tabular}


It can be seen that the quality of bio-diesel from GTW is the same as that of rape seed oil and soybean oil [4]. China's bio-diesel industry has three characteristics: (i) The first is the esterification that happens simultaneously with the trans-esterification reaction, thus it can effectively convert fatty acid and neutral oil into bio-diesel at the same time, to avoid the separation and second reaction; (ii) The second is the vacuum distillation at the end of the whole process, which ensures the same quality for the final product, instead of the different raw material; (iii) The $3^{\text {rd }}$ is that no glycerol is produced in the technological process chain, which is relatively too short to produce glycerol, and what is more, the quantity of glycerol is small for the high AV of the raw material [4]. Then, the engine and road tests are carried out with the bio-diesel as the transportation fuel. The result shows that the performance is the same as the bio-diesel from other sources [3].

\section{CONCLUSIONS}

The greatest barrier to biodiesel use is its cost compared to conventional diesel fuel. However, there are large amounts of restaurant waste oils and rendered animal fats potentially available for biodiesel production. If it is not properly treated, GTW easily brings about mal-odor, gaseous pollution and oily water pollution to the environment, consequently becoming a headache to the wastewater treatment plant all over the world. If it is adequately exploited, GTW will serve as a new energy, either as biogas or bio-diesel. A special extraction technology has been developed in China, based on the chaos theory, where no external energy is needed and no mal-odor emission appears in the process. The bio-diesel obtained from the grease using this technology has the same quality and engine performance as the bio-diesel from soybean or rape seeds.

\section{REFERENCES}

[1] Canakci, M. 2007. The potential of restaurant waste lipids as biodiesel feedstocks. Bioresource Technology 98:183-190.

[2] Wiltsee, G. 1998. Waste Grease Resources in 30 US Metropolitan Areas. BioEnergy '98: Expanding BioEnergy Partnerships. p956-963.

[3] Xing, J., Li, L., Xuan, W. HeiHu, L. He, K.L. 2005. Study on the waste grease extraction technology from grease trap waste and its conversion to bio-diesel. China Resources Comprehensive Utilization. No.10, Oct.2005. Total Number 227, p12-16.

[4] Xing, J. Li, L., Xuan, W. 2007. How shall petroleum giants deal with the development tide ofebio-ethanol and bio-diesel (in preparation).

[5] Liu, K. 1994. Preparation of fatty acid methyl esters for gas-chromatographic analysis of lipids in biological materials. JAOCS 71 (11):1179-1187.

[6] Ward, J.D., Windsor, D.M. 1999. Grease Trap and Cooking Oil Waste Stream Cycle Audit. University of South Australia Research Project for the Green City Program. 17p. 